\title{
Inhibitor of DNA binding 3 reverses cisplatin resistance in human lung adenocarcinoma cells by regulating the PI3K/Akt pathway
}

\author{
FANG-FANG CHEN $^{1}$, XING LV ${ }^{1}$, QIN-FEI ZHAO ${ }^{1}$, YU-ZHONG XU $^{1}$, \\ SHU-SHENG SONG ${ }^{1}$, WEI YU ${ }^{1}$ and XIAO-JUN LI ${ }^{1,2}$ \\ ${ }^{1}$ Center of Clinical Laboratory Science, Jinling Hospital, School of Medicine, Nanjing University, \\ Nanjing, Jiangsu 210002; ${ }^{2}$ State Key Laboratory of Analytical Chemistry for Life Science, \\ Department of Chemistry, Nanjing University, Nanjing, Jiangsu 210093, P.R. China
}

Received March 9, 2017; Accepted January 26, 2018

DOI: $10.3892 / \mathrm{ol} .2018 .8849$

\begin{abstract}
Inhibitor of DNA-binding 3 (ID3) is a helixloop-helix transcription factor that is associated with cell proliferation, differentiation and drug resistance in human cancer, and with anticancer effects in certain types of cancer cells. The present study investigated whether and how ID3 was involved in multidrug resistance (MDR) in human cisplatin (DDP)-resistant A549/DDP lung adenocarcinoma cells. The underlying mechanism of action was investigated in vitro. Cell Counting Kit-8 (CCK-8) and flow cytometry assays demonstrated that overexpression of ID3 enhanced chemosensitivity and decreased drug efflux in A549/DDP cells. Reverse transcription-quantitative polymerase chain reaction revealed that the expression of anti-apoptotic gene B-cell lymphoma-2 was significantly downregulated in cells expressing exogenous ID3 $(\mathrm{P}<0.05)$. These results indicated that ID3 may synergize with DDP to increase apoptosis in A549/DDP cells. ID3 overexpression modulated the activity of phosphoinositide 3-kinase/RAC serine/threonine-protein kinase signaling and downregulated the expression of multi-drug resistance protein-1, indicating that ID3 expression can reverse multi-drug resistance in A549/DDP cells. Collectively, these results indicate that ID3 is a potential effective chemotherapeutic target for the treatment of human DDP-resistant A549 lung adenocarcinoma therapy.
\end{abstract}

\section{Introduction}

Lung cancer is the leading cause of cancer-associated mortality worldwide, with the majority of cases non-small cell lung cancer (NSCLC) (1). Platinum-based chemotherapy in combination with radiation therapy is the mainstream in

Correspondence to: Professor Xiao-Jun Li, Center of Clinical Laboratory Science, Jinling Hospital, School of Medicine, Nanjing University, 305 East Zhongshan Road, Nanjing, Jiangsu 210002, P.R. China

E-mail: xiaojunli62@126.com

Key words: inhibitor of DNA binding 3, multidrug resistance, A549/DDP, phosphoinositide 3-kinase, apoptosis patients with NSCLC treatment; however, chemoresistance limits the survival of patients with advanced disease that are receiving chemotherapy (2). Cisplatin (DDP) is one of the most commonly used chemotherapeutic agents for patients with lung cancer owing to its high efficiency, relatively mild side effects and ease of administration. However, DDP resistance often occurs in clinical practice (3). Therefore, investigation of the mechanisms of drug resistance may accelerate the identification of novel therapeutic targets and strategies for the treatment of NSCLC (4).

Multidrug resistance (MDR) is a major obstacle of successful chemotherapy treatment. Thus, an improved understanding of the different mechanisms underlying MDR or searching for effective MDR modulators represents a promising strategy to overcome drug resistance. Several major mechanisms of drug resistance in cancer cells have been identified, including alterations to drug metabolism and apoptosis pathways, deficiencies in DNA repair pathways that induce resistance to chemotherapy and overexpression of ATP-binding cassette $(\mathrm{ABC})$ transporters that are involved in the efflux of chemotherapeutic drugs (5-7). The phosphoinositide 3-kinase (PI3K)/RAC serine/threonine-protein kinase (Akt) signaling pathway has a substantial role in drug resistance by enabling tumor cells to escape apoptosis (8). The PI3K/Akt signaling pathway has been reported to control the expression and function of the numerous proteins essential for tumor cell drug resistance $(9,10)$.

Inhibitor of DNA binding 3 (ID3) is a member of the ID family of genes, which are key regulators of cellular proliferation, differentiation, apoptosis, tumorigenesis and carcinogenesis (11-13). A previous study demonstrated that ID3 induced apoptosis in immortalized human keratinocytes upon exposure to ultraviolet $\mathrm{B}$ radiation, consistent with its role as a tumor suppressor (14). ID3 synergizes with 5-FU and DDP therapies for non-melanoma skin cancer cells, and mediates apoptosis in A431 cells via the ETS domain-containing protein Elk-1/caspase-8-dependent pathway (15). Overexpression of ID3 has been documented to trigger apoptosis in A549 human lung adenocarcinoma cells $(16,17)$, meaning that it could serve as a novel strategy for inhibiting DDP-sensitive lung cancer (18). Thus, there may be a link between the ability of ID3 to induce apoptosis and function as a tumor suppressor gene. 
ID3, as a regulator of apoptosis whose expression is induced by antineoplastic agents, has the potential to enhance the sensitivity of chemotherapy. However, whether and how ID3 is involved in regulating DDP resistance in A549/DDP cells remains unclear. The present study revealed that overexpression of ID3 induced apoptosis in A549/DDP cells and enhanced the sensitivity of A549/DDP cells to DDP treatment. In addition, the results of the present study also indicated that ID3 exerted its tumor-suppressing activity by directly suppressing the PI3K/Akt signaling pathway. These results may provide novel insights into the molecular mechanisms of DDP resistance induced by overexpression of ID3 levels in lung adenocarcinoma cells and indicate that ID3 may represent a novel therapeutic target for the reversal of DDP resistance in lung adenocarcinoma cells.

\section{Materials and methods}

Cell culture. The DDP-resistant A549/DDP cell line and native A549 cells were purchased from the Cancer Institute of the Chinese Academy of Medical Sciences (Beijing, China). Cells were cultured as previously described (18). In all experiments, cells were grown in culture medium to $70 \%$ confluence in 100-mm tissue culture dishes. Cells were serum-starved for $24 \mathrm{~h}$.

Transient transfection. Briefly, A549 and A549/DDP cells $\left(2.5 \times 10^{5}\right.$ cells $\left./ \mathrm{ml}\right)$ were seeded in 6 -well plates and incubated overnight. Cells were then transfected with pEGFP/ID3 (4 $\mu \mathrm{g} / \mu 1$, overexpression ID3 vectors) and pEGFP/control (4 $\mu \mathrm{g} / \mu 1$, control vectors) plasmid, which were purchased from Nanjing Realgene Co., Ltd. (Nanjing, China) using Lipofectamine 2000 (Invitrogen; Thermo Fisher Scientific, Inc., Waltham, MA, USA), according to the manufacturer's protocol. After $24 \mathrm{~h}$, cells were collected, followed by reverse transcription-quantitative polymerase chain reaction (RT-qPCR), western blot analysis, or cell viability determined by CCK-8.

CCK-8 assay for proliferation activity. A549/DDP cells $\left(1 \times 10^{4}\right.$ cells $\left./ \mathrm{ml}\right)$ that were untransfected, transfected with pEGFP/ID3 or transfected with pEGFP/control were seeded into 96-well plates and incubated with various concentrations of DDP $(0,0.5,1.0,2.0,5.0,10,15,20,30,40$ and $80 \mu \mathrm{g} / \mathrm{ml})$ for $24 \mathrm{~h}$ in quadruplicate. Next, $10 \mu \mathrm{l} \mathrm{CCK-8} \mathrm{(Dojindo} \mathrm{Molecular}$ Technologies, Inc., Shanghai, China) solution was added to every well and cells were incubated for a further $4 \mathrm{~h}$. The optical density (OD) was then measured at $570 \mathrm{~nm}$ using a microplate reader. The inhibition rate was calculated as follows: Inhibition rate $(\%)=\left(1-\mathrm{OD}_{570 \mathrm{~nm}}\right.$ value of experimental group/OD $\mathrm{OD}_{570 \mathrm{~nm}}$ value of control group) $\mathrm{x} 100$. From this, the half-maximal inhibitory concentration $\left(\mathrm{IC}_{50}\right)$ was calculated. The reversal fold ( $\mathrm{RF}$ ) values were calculated using the following formula: $\mathrm{RF}=\mathrm{IC}_{50}$ of $\mathrm{pEGFP-ID3}$ group/ $\mathrm{IC}_{50}$ of the pEGFP group. The experiments were repeated three times.

Annexin V-fluorescein isothiocyanate (FITC)/propidium iodide (PI) apoptosis assay. Transfected and untransfected A549/DDP cells $\left(3.5 \times 10^{5}\right.$ cells $\left./ \mathrm{ml}\right)$ were seeded into 12 -well plates and incubated with $0,1.0$ or $2.0 \mu \mathrm{g} / \mathrm{ml}$ DDP for $24 \mathrm{~h}$.
The A549/DDP cells were then washed with 1X PBS and resuspended in $100 \mu \mathrm{l}$ binding buffer (Sigma-Aldrich; Merck KGaA, Darmstadt, Germany). Next, Annexin V-FITC and PI (Sigma-Aldrich; Merck KGaA) were added for $30 \mathrm{~min}$ at $37^{\circ} \mathrm{C}$ in the dark. Following dilution with $400 \mu \mathrm{l}$ binding buffer, staining was analyzed within $1 \mathrm{~h}$ by flow cytometry. The fluorescence intensity (green, FL1-H; red, FL2-H) was measured using a FACSCalibur flow cytometer (BD Biosciences, San Jose, CA, USA). CellQuest Pro software 5.1 (BD Biosciences) was used for acquisition and analysis of data.

RT-qPCR analysis. Total RNA was isolated from A549 and A549/DDP cells, using TRIzol reagent (Invitrogen, Thermo Fisher Scientific, Inc.) in accordance with the manufacturer's protocol. The concentration and purity of the RNA samples were determined using Eppendorf Biophotometer (Eppendorf, Hamburg, Germany). In total, $1 \mu \mathrm{g}$ of total RNA was used to synthesize cDNA. cDNA was obtained by reverse transcription with the PrimeScript RT Master Mix (Takara Bio, Inc., Otsu, Japan). qPCR was performed using the FastStart Universal SYBR Green Master (Rox) (Roche Applied Science, Rotkreuz, Switzerland) with ABI 7500 Real Time PCR system (Applied Biosystems, CA, USA). The primers were designed with software Premier 5.0 (Premier Biosoft International, Palo Alto, CA, USA) and synthesized by Sangon Biotech Co., Ltd. (Shanghai, China). The sequences of the primers are depicted in Table I. The thermocycling conditions were as follows: $95^{\circ} \mathrm{C}$ for $4 \mathrm{~min}$, followed by 40 cycles of $95^{\circ} \mathrm{C}$ for $40 \mathrm{sec}$ and $60^{\circ} \mathrm{C}$ for $30 \mathrm{sec}$, and final elongation at $72^{\circ} \mathrm{C}$ for $5 \mathrm{~min}$. GAPDH was used as an internal control, and the fold change was calculated using the $2^{-\Delta \Delta \mathrm{Cq}}$ method (19). PCR was performed in triplicate.

Flow cytometry analysis. A549/DDP cells $\left(3.5 \times 10^{5}\right.$ cells $\left./ \mathrm{ml}\right)$ transfected with $\mathrm{pEGFP/ID3} \mathrm{or} \mathrm{pEGFP/control,} \mathrm{or} \mathrm{untrans-}$ fected cells were washed with 1 XPBS buffer and resuspended in $200 \mu$ l cell staining buffer (Beyotime Institute of Biotechnology, Shanghai, China). After blocking with $10 \%$ fetal bovine serum (FBS; HyClone Laboratories, Inc.) at $4^{\circ} \mathrm{C}$ for $1 \mathrm{~h}$ to minimize non-specific background signals, $5 \mu \mathrm{l}$ allophycocyanin (APC)-conjugated anti-human multi-drug resistant protein-1 (MDR-1) antibody (ready to use dilution; cat. no. 348607; BioLegend, San Diego, CA, USA) was added for 10-15 min at $37^{\circ} \mathrm{C}$ in the dark. The expression of MDR-1 protein on the cell membrane was detected using a FACSCalibur flow cytometer (BD Biosciences, San Jose, CA, USA). CellQuest Pro software 5.1 (BD Biosciences) was used for acquisition and analysis of data.

Western blotting assay. Cells from each group were cultured in the 6-well plates were washed in PBS and lysed in Radioimmunoprecipitation Assay lysis buffer (Beyotime Institute of Biotechnology, Shanghai, China). Protein concentrations was quantified by BCA Protein Assay kit (Beyotime Institute of Biotechnology), Equal amounts of protein $(20 \mu \mathrm{g})$ were separated by $10 \%$ SDS-PAGE and transferred onto polyvinylidene difluoride membranes (EMD Millipore, Billerica, MA, USA). After membranes were blocked with 5\% skim milk in TBS containing $0.2 \%$ Tween-20 at room temperature for $2 \mathrm{~h}$, the membranes were incubated overnight at $4^{\circ} \mathrm{C}$ with primary antibodies comprising anti-MDR-1antibody 
Table I. Primer sequences used in reverse transcription-quantitative polymerase chain reaction.

\begin{tabular}{llll}
\hline Gene & Direction & Primer sequence & Product length, bp \\
\hline ID3 & Forward & 5'-ATGAAGGCGCTGAGCCCGGTGC-3' & 360 \\
& Reverse & 5'-CGGCCGAGTCAGTGGCAAAAGC-3' & 123 \\
Bcl-2 & Forward & 5'-GGGTGGGAGGGAGGAAGAATTT-3' & 180 \\
& Reverse & 5'-GCATCACATCGACCCCAATACAG-3' & \\
& Forward & 5'-CAACTAAGCGGCACAGAATG-3' &
\end{tabular}

ID3, inhibitor of DNA binding 3; Bcl-2, B-cell lymphoma-2; bp, base pairs.

(cat. no. ab-170904; 1:400; Abcam, Cambridge, UK), anti-RhoE antibody (cat. no. sc-53874; 1:400; Santa Cruz Biotechnology, Inc., Dallas, TX, USA), anti-PI3K antibody (cat. no. ab-40776; 1:400; Abcam). Subsequently, membranes were washed three times, and then incubated with horseradish peroxidase-conjugated anti-rabbit (cat. no. sc-51687; 1:1,000; Santa Cruz Biotechnology, Inc.) or anti-mouse secondary antibodies (cat. no. sc-2954; 1:1,000; Santa Cruz Biotechnology, Inc.) for $1 \mathrm{~h}$ at room temperature. Anti- $\beta$-actin antibody (cat. no. sc-47778; 1:500; Santa Cruz Biotechnology, Inc.) was used as a control. Immunoreactive bands were visualized by Enhanced Chemiluminescence Western Blotting Detection Reagents (GE Healthcare Life Sciences, Little Chalfont, UK) according to the manufacturer's protocol. The densitometric analysis of the bands was performed using ImageJ software (v.2.0; National Institutes of Health, Bethesda, MD, USA).

Statistical analysis. Statistical analysis was performed using SPSS 16.0 (SPSS, Inc., Chicago, IL, USA). The statistical difference of data between groups was analyzed by one-way analysis of variance (ANOVA) or Student's t-test. Student-Newman-Keuls (SNK) was used as a post hoc test following ANOVA. Data are expressed as the means \pm standard deviation. $\mathrm{P}<0.05$ was considered to indicate a statistically significant difference.

\section{Results}

The expression of ID3 mRNA in A549 and A549/DDP cells was detected by fluorescent quantitative PCR. The expression of ID3 was detected by RT-qPCR. Owing to the low level of expression of ID3 in A549 and A549/DDP cells, ID3 was overexpressed to elucidate the direct implication of ID3 in the chemosensitivity of A549/DDP cells. As shown in Fig. 1, the expression of ID3 was significantly increased in A549/DDP cells transfected with pEGFP/ID3 compared with those transfected with the empty vector or untransfected cells at the mRNA level.

Raised sensitivity of chemotherapy in A549/DDP cells owing to ID3 overexpression. Following pEGFP/ID3 transfection, the growth of A549/DDP cells was evaluated using a CCK-8 assay. As shown in Fig. 2A, the $\mathrm{IC}_{50}$ of DDP in A549/DDP cell decreased from 19.38 to $11.71 \mu \mathrm{g} / \mathrm{ml}$, representing a 1.66 -fold

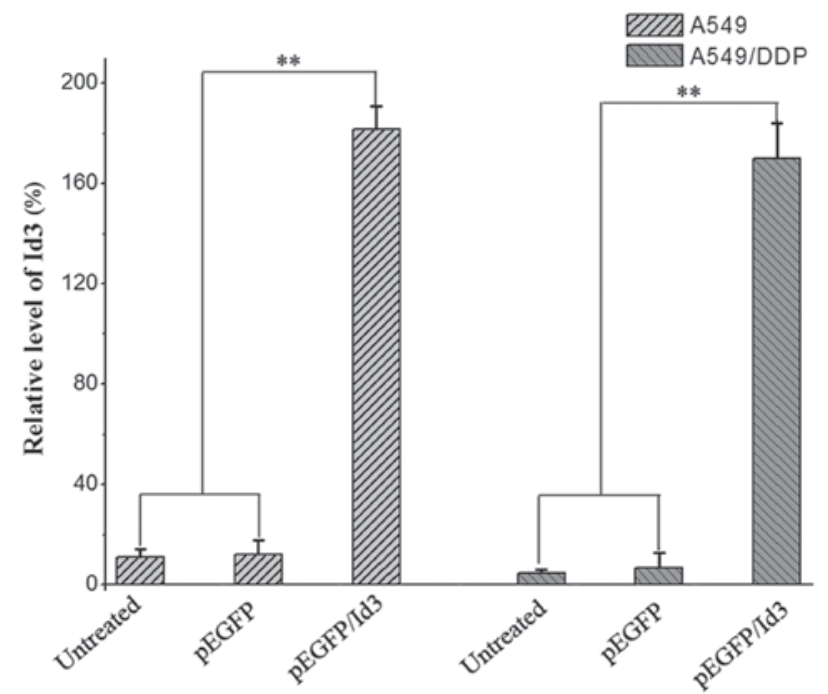

Figure 1. Expression of ID3 in the human lung adenocarcinoma A549 cell line and the DDP-resistant A549/DDP cell line. At $24 \mathrm{~h}$ after transfection, reverse transcription-quantitative polymerase chain reaction analysis was performed to detect the expression of ID3. Compared with untransfected and pEGFP/control-transfected cells, the expression of ID3 was significantly increased in ID3/pEGFP-transfected A549 and A549/DDP cells. GAPDH served as an internal reference. Detection was performed in triplicate. ${ }^{* *} \mathrm{P}<0.01$. ID3, inhibitor of DNA binding 3; DDP, cisplatin; EGFP, enhanced green fluorescent protein.

increase in DDP sensitization after ID3 transfection. The results of the CCK- 8 assay demonstrated that ID3 expression and DDP treatment had synergistic effect on the inhibition of cell growth, and the synergistic effect was caused by the change of biological characteristics of A549/DDP cells following ID3 induction.

After transfection with pEGFP/ID3, A549/DDP cells were treated with DDP at different concentrations $(0.0,1.0$ or $2.0 \mu \mathrm{g} / \mathrm{ml})$ and the apoptotic rate were detected by Annexin V-FITC/PI double staining. As depicted in Fig. 2B and C, the apoptotic rate of A549/DDP cells transfected with pEGFP/ID3 group was significantly higher than that of $\mathrm{pEGFP/control} \mathrm{group}(\mathrm{P}<0.05)$, and the apoptotic rate increased with the increase of DDP concentration, indicating that ID3 and DDP have a synergistic effect on cell apoptosis. This evidence further demonstrated that ID3 serves a key role in the mechanism of reversal of DDP resistance in human lung adenocarcinoma cells, potentially due to the overexpression 

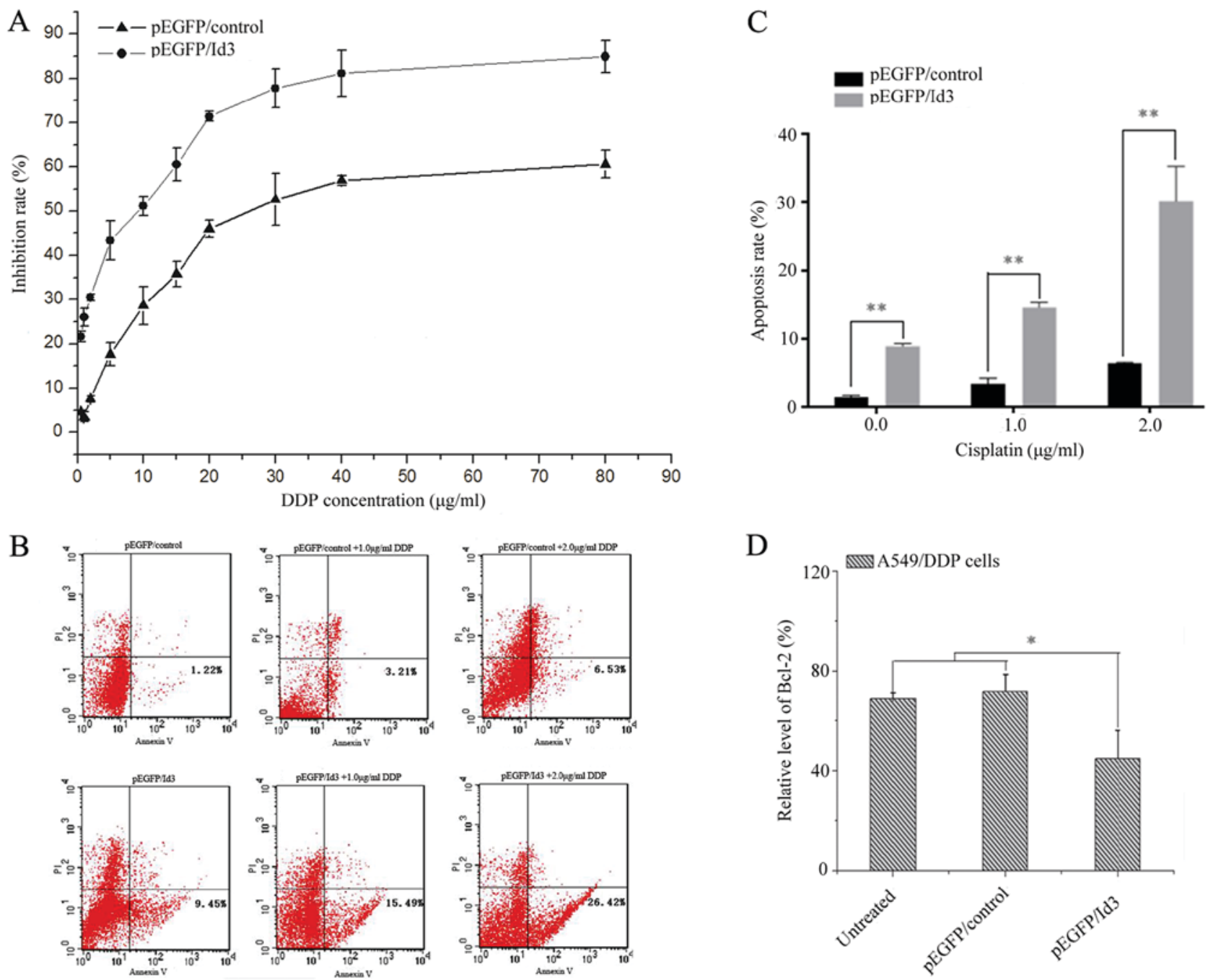

Figure 2. ID3 enhances DDP sensitivity and increases apoptosis in A549/DDP cells. (A) The growth inhibitory effect of ID3/pEGFP on A549 and A549/DDP cells at different DDP concentrations $(0,0.5,1.0,2.0,5.0,10,15,20,30,40$ and $80 \mu \mathrm{g} / \mathrm{ml})$. (B) Flow cytometry analysis of apoptosis in pEGFP/control or pEGFP/ID3-transfected A549/DDP cells combined with various concentrations of DDP (0.0, 1.0 or $2.0 \mu \mathrm{g} / \mathrm{ml})$. (C) The percentage of apoptotic cells in cells transfected with ID3 and treated with DDP was significantly higher than that in the pEGFP/control group. ${ }^{* *} \mathrm{P}<0.01 \mathrm{vs.} \mathrm{pEGFP/control} \mathrm{group.} \mathrm{(D)} \mathrm{After}$ A549/DDP cells were transfected with ID3/pEGFP or pEGFP/control for $24 \mathrm{~h}$, the levels of Bcl-2 expression were assessed by reverse transcription-quantitative polymerase chain reaction analysis. ${ }^{*} \mathrm{P}<0.05$ vs. pEGFP/control group and blank cells. GAPDH served as an internal reference. Experiment was performed in triplicate. "P<0.05. ID3, inhibitor of DNA binding 3; DDP, cisplatin; EGFP, enhanced green fluorescent protein; Bcl-2, B-cell lymphoma-2.

of ID3, which results in a series of biological effects leading to enhancement of the sensitivity of DDP in A549/DDP cells, resulting in apoptosis, and reversal of drug resistance.

The results of the western blotting assay demonstrated that the expression of anti-apoptotic gene $\mathrm{Bcl}-2$ was significantly downregulated in $\mathrm{pEGFP/ID3}$ transfected cells $(\mathrm{P}<0.05$; Fig. 2D), indicating that ID3 may be involved in apoptosis as part of the upstream regulatory/apoptotic-associated genes, thus reversing drug resistance.

Inhibition of MDR-mediated transport due to ID3 overexpression. To investigate the possible molecular mechanism of the ID3-dependent reversal of DDP resistance and promotion of apoptosis in tumor cells, the changes in the expression of multidrug resistance-associated genes was assessed. The results of this analysis revealed that the expression of RhoE protein was increased in pEGFP/ID3 transfected cells compared with the empty vector group (Fig. 3A). Furthermore, western blotting and flow cytometry analysis (Fig. 3B and C) revealed that the expression of MDR-1 was significantly downregulated in pEGFP/ID3 transfected cells. This result indicated that the efflux functions mediated by MDR-1 were significantly inhibited following ID3 overexpression. The data indicated that ID3 may be implicated in key steps of the development of multi-drug resistance in human lung adenocarcinoma cells.

ID3 overexpression results in the inhibition of PI3K/Akt signaling. The PI3K/Akt pathway is one of the most notable signaling pathways in cell apoptosis. The activation of the $\mathrm{PI} 3 \mathrm{~K} / \mathrm{Akt}$ signaling pathway is involved in the regulation of cell survival and glycogen metabolism. It is closely associated with the inhibition of tumor cell apoptosis and the occurrence and development of tumors. Akt activity is positively associated with drug resistance in lung, ovarian and breast cancer (20). The present study assessed the activity of PI3K/Akt signaling by $\mathrm{pEGFP/ID3} \mathrm{transfection} \mathrm{in} \mathrm{A549/DDP} \mathrm{cells.} \mathrm{Western}$ 
A
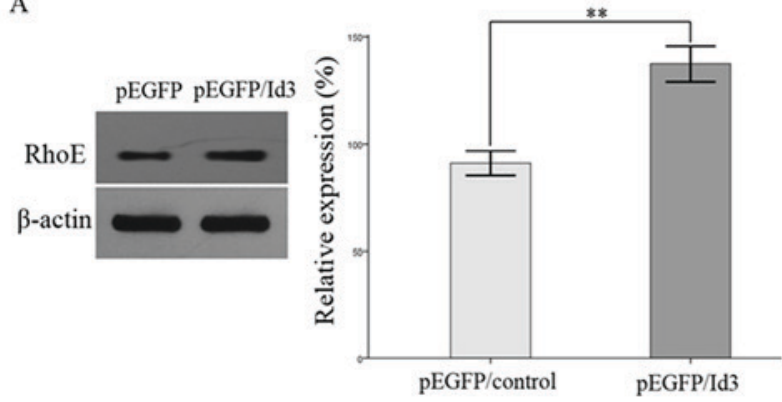

C
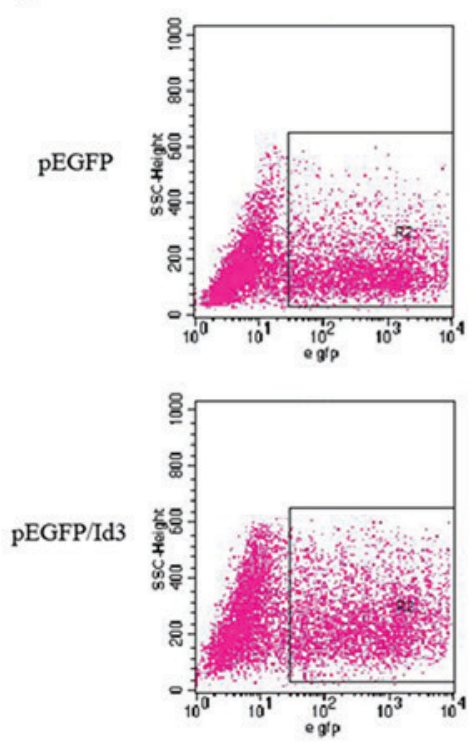

A549/DDP
B

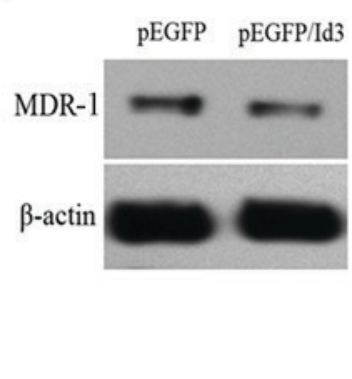

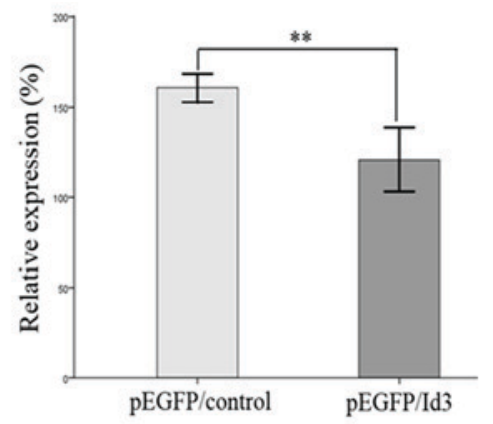
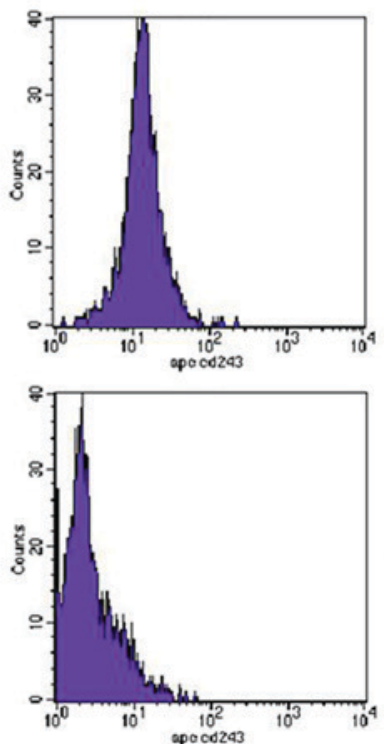

Figure 3. ID3 decreases the expression levels of multi-drug resistance proteins. (A) Detection of RhoE by western blot analysis. RhoE protein expression was significantly upregulated in the pEGFP/ID3-transfected A549/DDP cells as compared with pEGFP/control group. $\beta$-actin served as the loading control. (B) The MDR-1 protein levels in DDP resistant cells were identified by western blot. Results revealed that the expression of MDR-1 was downregulated significantly in pEGFP/ID3-transfected A549/DDP cells as compared with pEGFP/control group. $\beta$-actin served as an internal control for loading. (C) The results of flow cytometry demonstrated a decrease in MDR-1 protein levels in pEGFP/ID3-transfected A549/DDP cells as compared with pEGFP/control group. ${ }^{* *} \mathrm{P}<0.01$ vs. pEGFP/control group. ID3, inhibitor of DNA binding 3; DDP, cisplatin; EGFP, enhanced green fluorescent protein; RhoE, Rho-related GTP-binding protein RhoE; MDR-1, multi-drug resistance protein-1.

blotting (Fig. 4) revealed that the phosphorylation of Akt was significantly decreased following pEGFP/ID3 transfection, compared with the empty vector group $(\mathrm{P}<0.05)$. Conversely, overexpression of ID3 inhibited PI3K/Akt signaling pathway activity, thereby inhibiting tumor cell proliferation and reversing of drug resistance.

\section{Discussion}

ID3 is considered to have multiple roles in the regulation of cell growth; it was identified as a tumor suppressor gene for Burkitt's lymphoma (21). Kee et al (22) proposed that the induction of apoptosis by the retroviral-mediated expression of ID3 in B lymphocyte progenitors (BLPs) by transforming growth factor- $\beta 1$-mediated signaling. In addition, Genetic aberrations to ID3 indicate that it may function as a tumor suppressor (23). It has been recognized that ID3 serves as an inducer of apoptosis in response to X-ray irradiation via the regulation of endogenous $\beta$-catenin level (24). Evidence has also demonstrated that ID3 induced apoptosis in immortalized human keratinocytes (14). Recently, it was reported that ID3-induced apoptosis is mediated through its HLH
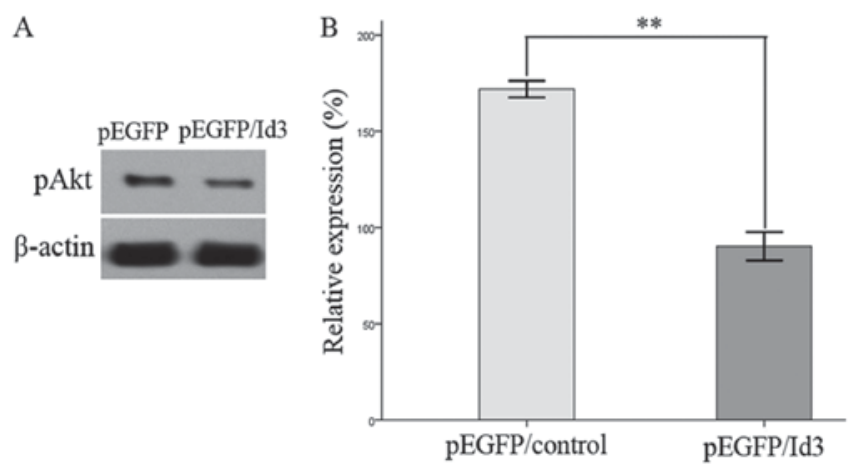

Figure 4. Effect of ID3 gene expression on the phosphorylation of Akt in A549/DDP cells. (A and B) Detection of pAkt by western blot analysis. pAkt levels were significantly downregulated in pEGFP/ID3-transfected A549/DDP cells. $\beta$-actin served as an internal control for loading. ${ }^{* *} \mathrm{P}<0.01$ vs. the $\mathrm{pEGFP/control} \mathrm{group.} \mathrm{pAkt,} \mathrm{phosphorylated} \mathrm{RAC} \mathrm{serine/threonine-}$ protein kinase; ID3, inhibitor of DNA binding 3; DDP, cisplatin; EGFP, enhanced green fluorescent protein.

and C-terminal domains. ID3 also sensitized SCC cells to chemotherapeutic agents, including DDP and 5-fluorouracil 
(5-FU), via Elk-1/caspase-8-dependent apoptotic pathway (15). Previous studies found that exogenous ID3 expression induced inhibition of proliferation and apoptosis in A549 cells and A549/DDP cells (16-18). The present study aimed to determine whether ID3 overexpression could enhance the sensitivity of lung cancer cells to DDP.

Inhibitor of differentiation/DNA binding (Id) proteins, which are negative regulators of basic helix-loop-helix (bHLH) transcription factors, function as dominant-negative inhibitors of E-proteins by inhibiting their ability to bind DNA (12). ID3 belongs to the ID family and acts as a negative regulator that inhibits apoptosis by anticancer drugs (25), which is expected to become a novel therapeutic target for enhancing sensitivity to chemotherapy. ID3 has been shown to sensitize sarcoma cells and A431 cells to DDP and 5-FU, respectively (26). A previous study revealed that ID1 is a molecular marker of lung cancer prognosis, and downregulation of the expression of ID1 could increase the sensitivity of lung cancer chemotherapy; however, its mechanism remains unclear (27). Additional evidence revealed that downregulation of ID1 can enhance the sensitivity of gastric cancer MGC803 and AGS cells to DDP (28). ID1 and ID3 co-expression was associated with a poor clinical outcome in patients with locally advanced NSCLC treated with chemoradiotherapy (29). The results of the present study indicated that ID3 serves an important role in cisplatin resistance in lung adenocarcinoma, and demonstrated that ID3 overexpression may enhance cisplatin chemosensitivity and resulted in markedly attenuated growth inhibition of tumor cells. However, to the best of our knowledge, no study exists concerning the specific mechanism of apoptosis driven by ID3 in human lung adenocarcinoma cells and the mechanism of resistance reversal in A549/DDP.

Bcl-2 can suppress apoptosis, leading to the generation of drug resistance in several cell types (30). Bcl-2-transfected cancer cells became more resistant to DDP $(30,31)$. Therefore, the expression of Bcl-2 is closely associated with drug resistance in tumor cells. The results of RT-qPCR in the present study revealed that the expression of e anti-apoptotic gene Bcl-2 was significantly downregulated in pEGFP/ID3-transfected cells, indicating that ID3 may be involved in apoptosis as part of the upstream/anti-apoptosis-associated genes to reverse cell resistance.

Drug resistance is the primary reason for the failure of cancer treatments (1). MDR is the main cause of chemotherapy failure, leading to the recurrence of cancer (32). Thus it is important to find effective methods to reverse MDR. The present study demonstrated that the expression of MDR-1 in A549/DDP cells transfected with pEGFP/ID3 was significantly downregulated, as analyzed using flow cytometry and western blot analysis $(\mathrm{P}<0.05)$, indicating that ID3 overexpression reverses DDP resistance in A549/DDP cells. Notably, ID3 transgene expression increased the expression of RhoE, which may result in inhibition of tumor growth. These results are consistent with those of recent studies, which revealed that the downregulation of RhoE expression in lung cancer cell lines and other cancerous tissues may contribute to the invasion and metastasis of tumor cells $(33,34)$.

Taken together, the results of the present study demonstrated that ID3 overexpression in A549/DDP cells inhibited DDP resistance by suppressing activation of the
PI3K/Akt signaling pathway. Therefore, overexpression of ID3 may be a potential approach to reverse DDP resistance in DDP-resistant human lung adenocarcinoma cells. However, the exact molecular mechanisms of tumor MDR require further investigation.

\section{Acknowledgements}

Not applicable.

\section{Funding}

The present study was supported by grants from the National Natural Science Foundation of China (grant no. NSFC-81171652), the Jiangsu Province Science and Technology Program (grant no. BL2014072) and the National Clinical Key Program (grant no. 2014ZDZK003).

\section{Availability of data and materials}

All data generated or analyzed during this study are included in this published article.

\section{Authors' contributions}

FC and QZ conceptualized the experiments. XLv analyzed the data. YX performed the statistical analysis. SS performed cell experiments and flow cytometry. WY contributed to study design. XLi contributed to study design and manuscript writing.

\section{Ethics approval and consent to publish}

Not applicable.

\section{Consent for publication}

Not applicable.

\section{Competing interests}

The authors declare that they have no competing interests.

\section{References}

1. Siegel RL, Miller KD and Jemal A: Cancer statistics, 2018. CA Cancer J Clin 68: 7-30, 2018.

2. Kievit FM, Wang FY, Fang C, Mok H, Wang K, Silber JR, Ellenbogen RG and Zhang M: Doxorubicin loaded iron oxide nanoparticles overcome multidrug resistance in cancer in vitro. J Control Release 152: 76-83, 2011

3. Tan XL, Moyer AM, Fridley BL, Schaid DJ, Niu N, Batzler AJ, Jenkins GD, Abo RP, Li L, Cunningham JM, et al: Genetic variation predicting cisplatin cytotoxicity associated with overall survival in lung cancer patients receiving platinum-based chemotherapy. Clin Cancer Res 17: 5801-5811, 2011.

4. Chen G, Umelo IA, Lv S, Teugels E, Fostier K, Kronenberger P, Dewaele A, Sadones J, Geers C and De Grève J: miR-146a inhibits cell growth, cell migration and induces apoptosis in non-small cell lung cancercells. PLoS One 8: e60317, 2013.

5. Gottesman MM: Mechanisms of cancer drug resistance. Annu Rev Med 53: 615-627, 2002.

6. Johnstone RW, Ruefli AA and Lowe SW: Apoptosis: A link between cancer genetics and chemotherapy. Cell 108: 153-164, 2002. 
7. Szakács G, Paterson JK, Ludwig JA, Booth-Genthe C and Gottesman MM: Targeting multidrug resistance in cancer. Nat Rev Drug Discov 5: 219-234, 2006.

8. Burris HA III: Overcoming acquired resistance to anticancer therapy: Focus on the PI3K/Akt/mTOR pathway. Cancer Chemother Pharmacol 71: 829-842, 2013.

9. Li L, Wei XH, Pan YP, Li HC, Yang H, He QH, Pang Y, Shan Y, Xiong FX, Shao GZ and Zhou RL: LAPTM4B: A novel cancer-associated gene motivates multidrug resistance through efflux and activating PI3K/Akt signaling. Oncogene 29: 5785-5795, 2010

10. Lin X, Zhang $X$, Wang Q, Li J, Zhang $P$, Zhao $M$ and Li X: Perifosine downregulates MDR1 gene expression and reverses multidrug-resistant phenotype by inhibiting PI3K/Akt/NF-kappaB signaling pathway in a human breast cancer cell line. Neoplasma 59: 248-256, 2012.

11. Lasorella A, Uo T and Iavarone A: Id proteins at the cross-road of development and cancer. Oncogene 20: 8326-8333, 2001.

12. Ruzinova MB and Benezra R: Id proteins in development, cell cycle and cancer. Trends Cell Biol 13: 410-418, 2003.

13. Rotzer D, Krampert M, Sulyok S, Braun S, Stark HJ, Boukamp P and Werner S: Id proteins: Novel targets of activin action, which regulate epidermal homeostasis. Oncogene 25: 2070-2081, 2006.

14. Simbulan-Rosenthal CM, Daher A, Trabosh V, Chen WC, Gerstel D, Soeda E and Rosenthal DS: ID3 induces a caspase-3and -9-dependent apoptosis and mediates UVB sensitization of HPV16 E6/7 immortalized human keratinocytes. Oncogene 25 3649-3660, 2006.

15. Chen YS, Aubee J, DiVito KA, Zhou H, Zhang W, Chou FP, Simbulan-Rosenthal CM and Rosenthal DS: ID3 induces an Elk-1-caspase-8-dependent apoptotic pathway in squamous carcinoma cells. Cancer Med 4: 914-924, 2015.

16. Li XJ, Zhu CD, Yu W, Wang P, Chen FF, Xia XY and Luo B Overexpression of ID3 induces apoptosis of A549 human lung adenocarcinoma cells. Cell Prolif 45: 1-8, 2012.

17. Chen FF, Liu Y, Wang F, Pang XJ, Zhu CD, Xu M, Yu W and Li XJ: Effects of up-regulation of ID3 in human lung adenocarcinoma cells on proliferation, apoptosis, mobility and tumorigenicity. Cancer Gene Ther 22: 431-437, 2015.

18. Chen F, Zhao Q, Wang S, Wang H and Li X: Upregulation of ID3 inhibits cell proliferation and induces apoptosis in A549/DDP human lung cancer cells in vitro. Mol Med Rep 14: 313-318, 2016.

19. Livak KJ and Schmittgen TD: Analysis of relative gene expression data using real-time quantitative PCR and the 2(-Delta Delta C(T)) method. Methods 25: 402-408, 2001

20. Krystal GW, Sulanke G and Litz J: Inhibition of phosphatidylinositol 3-kinase-Akt signaling blocks growth, promotes apoptosis, and enhances sensitivity of small cell lung cancer cells to chemotherapy. Mol Cancer Ther 1: 913-922, 2002.

21. Schmitz R, Young RM, Ceribelli M, Jhavar S, Xiao W, Zhang M, Wright G, Shaffer AL, Hodson DJ, Buras E, et al: Burkitt lymphoma pathogenesis and therapeutic targets from structural and functional genomics. Nature 490: 116-120, 2012.

22. Kee BL, Rivera RR and Murre C: ID3 inhibits B lymphocyte progenitor growth and survival in response to TGF- $\beta$. Nat Immunol 2: 242-247, 2001.
23. Ellmeier W, Aguzzi A, Kleiner E, Kurzbauer R and Weith A Mutually exclusive expression of a helix loop-helix gene and $\mathrm{N}$-myc in human neuroblastom as and in normal development. EMBO J 11: 2563-2571, 1992.

24. Lee YS, Mollah ML, Sohn KC, Shi G, Kim DH, Kim KH, Cho MJ, Kim S, Lee YH, Kim CD and Lee JH: ID3 mediates $\mathrm{X}$-ray-induced apoptosis of keratinocytes through the regulation of $\beta$-catenin. J Dermatol Sci 60: 138-142, 2010.

25. Sachindra, Larribère L, Novak D, Wu H, Hüser L, Granados K, Orouji E and Utikal J: New role of ID3 in melanoma adaptive drug-resistance. Oncotarget 8: 110166-110175, 2017.

26. Koyama T, Suzuki H, Imakiire A, Yanase N, Hata K and Mizuguchi J: ID3-mediated enhancement of cisplatin-induced apoptosis in a sarcoma cell line MG-63. Anticancer Res 24: 1519-1524, 2004

27. Ponz-Sarvisé M, Nguewa PA, Pajares MJ, Agorreta J, Lozano MD, Redrado M, Pio R, Behrens C, Wistuba II, García-Franco CE, et al: Inhibitor of differentiation-1 as a novel prognostic factor in NSCLC patients with adenocarcinoma histology and its potential contribution to therapy resistance. Clin Cancer Res 17: 4155-4166, 2011.

28. Li W, Zhang CH, Hong YL, Li J, Hu YM and Zhao CF: Inhibitor of DNA-binding-1/inhibitor of differentiation-1 (ID-1) is implicated in various aspects of gastric cancer cell biology. Mol Biol Rep 39: 3009-3015, 2012.

29. Castañon E, Bosch-Barrera J, López I, Collado V, Moreno M, López-Picazo JM, Arbea L, Lozano MD, Calvo A and Gil-Bazo I: Id1 and ID3 co-expression correlates with clinical outcome in stage III-N2 non-small cell lung cancer patients treated with definitive chemoradiotherapy. J Transl Med 11: 13, 2013.

30. Yip KW and Reed JC: Bcl-2 family proteins and cancer. Oncogene 27: 6398-6406, 2008.

31. Yoon SS, Ahn KS, Kim SH, Shim YM and Kim J: In vitro establishment of cis-diammine-dichloroplatinum (II) resistant lung cancer cell line and modulation of apoptotic gene expression as a mechanism of resistant phenotype. Lung Cancer 33: 221-228, 2001.

32. Ozben T: Mechanisms and strategies to overcome multiple drug resistance in cancer. FEBS Lett 580: 2903-2909, 2006.

33. Grise F, Sena S, Bidaud-Meynard A, Baud J, Hiriart JB, Makki K, Dugot-Senant N, Staedel C, Bioulac-Sage P, Zucman-Rossi J, et al: Rnd3/RhoE is down-regulated in hepatocellular carcinoma and controls cellular invasion. Hepatology 55: 1766-1775, 2012.

34. Wang H, Wang Y, Liang B, He F, Li Y, Che J, Li X, Zhao H and Shi G: The Rho GTPase RhoE exerts tumor-suppressing effects in human esophageal squamous cell carcinoma via negatively regulating epidermal growth factor receptor. J Cancer Res Ther 12 (Suppl): S60-S63, 2016.

(i) $($ This work is licensed under a Creative Commons Attribution-NonCommercial-NoDerivatives 4.0 International (CC BY-NC-ND 4.0) License. 